\title{
Desenvolvimento do psiquismo e formação de conceitos científicos: apontamentos para a Educação Física
}

\author{
Matheus Bernardo Silva \\ Universidade Federal do Paraná - Curitiba - PR - Brasil
}

\begin{abstract}
Resumo
O objetivo principal do artigo é contribuir com a discussão sobre a formação de conceitos científicos no âmbito da Educação Física escolar. Enfatizaa reflexão sobre a formação de conceitos científicos da cultura corporal, que consideramos como o objeto de conhecimento da Educação Física. Trata-se de um trabalho teórico-bibliográfico, balizado pelos referenciais da psicologia histórico-cultural e da pedagogia histórico-crítica. Levantou-se a hipótese de que o trato com a cultura corporal, no interior da prática pedagógica, deve enfocar a formação de conceitos científicos, em proveito da elevação do pensamento teórico-científico do aluno. Para tanto, abordaram-se as seguintes questões: análise do desenvolvimento do psiquismo humano; conceptualização da cultura corporal; explicitação de elementos didático-metodológicos para a prática pedagógica, com ênfase na formação de conceitos científicos. Confirma-se a hipótese levantada de que a efetivação da prática pedagógica da Educação Física com a formação de conceitos científicos da cultura corporal pode contribuir para o desenvolvimento teórico-científico do aluno.
\end{abstract}

Palavras-chave: Educação Física Escolar; métodos de ensino; aprendizagem escolar.

\section{Development of the psyche and formation of scientific concepts: notes for Physical Education}

\begin{abstract}
The main objective of the article is to contribute with the discussion about the formation of scientific concepts in the scope of the Physical Education in school. This article emphasizes the reflection on the formation of scientific concepts of body culture, which we consider as the object of knowledge of Physical Education. It is a theoretical-bibliographic work, based on the references of historical-cultural psychology and historical-critical pedagogy. It was hypothesized that the treatment of body culture, within the pedagogical practice, should focus on the formation of scientific concepts, to the benefit of the student's theoretical-scientific thinking. For that, the following questions were addressed: analysis of the development of the human psyche; conceptualization of body culture; explicitation of didactic-methodological elements for pedagogical practice, with emphasis on the formation of scientific concepts. It confirms the hypothesis raised that the effectiveness of the pedagogical practice of Physical Education with the formation of scientific concepts of body culture can contribute to the theoretical-scientific development of the student. Palavras-chave: Physical School Education; teaching methods; school learning.
\end{abstract}

\section{Desarrollo del psiquismo y formación de conceptos científicos: apuntamientos para la educación física}

\section{Resumen}

El objetivo principal del artículo es contribuir con la discusión sobre la formación de conceptos científicos en el ámbito de la Educación Física escolar. Se enfatiza la reflexión sobre la formación de conceptos científicos de la cultura corporal, que consideramos como el objeto de conocimiento de la Educación Física. Se trata de un estudio teórico-bibliográfico, balizado por los referenciales de la psicología histórico-cultural y de la pedagogía histórico-crítica. Se levantó la hipótesis de que el trato con la cultura corporal, en el interior de la práctica pedagógica, debe enfocar la formación de conceptos científicos, en provecho de la elevación del pensamiento teórico-científico del alumno. Para tanto, se abordaron las siguientes cuestiones: análisis del desarrollo del psiquismo humano; conceptualización de la cultura corporal; explicitación de elementos didáctico-metodológicos para la práctica pedagógica, con énfasis en la formación de conceptos científicos. Se confirma la hipótesis levantada de que la efectividad de la práctica pedagógica de la Educación Física con la formación de conceptos científicos de la cultura corporal puede contribuir para el desarrollo teórico-científico del alumno.

Palabras clave: Educación Física Escolar; métodos de enseñanza; aprendizaje escolar. 


\section{Considerações Iniciais}

O presente trabalho tem como objetivo contribuir com a prática pedagógica no campo da Educação Física escolar, tendo como principal escopo a formação de conceitos científicos, cujo proveito se dá na máxima possibilidade de desenvolvimento do psiquismo humano. A formação de conceitos científicos, de acordo com a psicologia histórico-cultural (Martins, 2013a; 2013b; Vigotski, 2010a; 2010b; 2012), contribui com a elevação do pensamento para um status teórico-científico. Eis aí a possibilidade de o ser humano compreender, na sua máxima possibilidade, o mundo real.

No caso específico da Educação Física escolar, partimos do pressuposto de que o seu objeto de conhecimento é a categoria cultura corporal, conforme adverte o Coletivo de Autores (1992). E, por conseguinte, deve-se atuar por meio de uma prática pedagógica que propicie ao indivíduo, inserido nesse processo, formar conceitos científicos no que se refere às atividades da cultura corporal.

A cultura corporal é parte das objetivações e apropriações que o ser humano efetiva no seu contato com a natureza. É na transformação da natureza, por meio do trabalho, que o ser humano produz a cultura e, por consequência, produz as atividades da cultura corporal. A cultura corporal, nesse sentido, parte da categoria trabalho como uma atividade humana realizada com dadas condições objetivas e subjetivas da existência do homem. Destarte, as atividades da cultura corporal são sistematizações elaboradas, construídas socialmente e desenvolvidas historicamente, que ocorrem por meio da atividade humana não material por não se separar do ato de produção. Caracterizamos, por exemplo, como atividades da cultura corporal, o jogo, a luta, a dança, o esporte, a brincadeira, entre outros.

A prática pedagógica, no âmago dessa área do conhecimento, deve ser dotada de elementos, didático-metodológicos que contribuam na compreensão da essência dessas atividades. A psicologia histórico-cultural, portanto, no que se refere à análise do desenvolvimento humano, possui embasamentos teórico-metodológico suficientes para compreender o processo de formação e apropriação de conceitos científicos. No entanto, é necessário que se tenha estratégias e ações metodológicas para que o aluno possa desenvolver tais conceitos e, assim, elevar o seu pensamento para o pensamento teórico-científico.

Concebemos, então, que a articulação entre os fundamentos da psicologia histórico-cultural e da pedagogia histórico-crítica (Scalcon, 2002; Martins, 2013a) contribuem, decisivamente, nesse processo de ensino, aprendizagem e desenvolvimento no âmbito da educação escolar e, consequentemente, da Educação Física.

Partindo desses pressupostos, apontamos como problematização, a ser discutida neste trabalho, as seguintes indagações: Qual a importância de dar ênfase, no âmbito da educação escolar e, por conseguinte, da Educação Física, na formação de conceitos científicos? Por que a Educação
Física tem como objeto de conhecimento a cultura corporal? Quais as contribuições da psicologia histórico-cultural e da pedagogia histórico-crítica para a prática pedagógica da Educação Física, cujo intuito se dá na formação de conceitos científicos da cultura corporal como contribuição para a elevação do pensamento teórico-científico do indivíduo?

O aporte teórico-metodológico que embasa o presente trabalho, de cunho teórico-bibliográfico, é o materialismo histórico-dialético (Marx, 2011). Com base nesse substrato teórico, pode-se compreender o objeto de estudo e os fenômenos que o circundam por meio das contradições que operam no interior do atual modo de produção e, por consequência, interferem no objeto de análise, possibilitando confrontá-lo com os determinantes histórico-sociais por meio de uma reflexão crítica, uma vez que todo fenômeno deve ser compreendido como parte de um processo histórico mais amplo, a educação e, portanto, a Educação Física está intimamente relacionada às transformações culturais e sociais (Sánchez Gamboa, 2012).

Assim, o trabalho está desenvolvido da seguinte maneira: 1) análise do processo de desenvolvimento do psiquismo humano, buscando compreender a importância da formação de conceitos científicos, de acordo com a psicologia histórico-cultural; 2) explicitação do conceito de cultura corporal e a justificativa dessa categoria por ser o objeto de conhecimento da Educação Física, conforme aponta o Coletivo de Autores (1992) e 3) apontamentos de elementos didático-metodológicos com base na articulação dos fundamentos da psicologia histórico-cultural e da pedagogia histórico-crítica.

\section{O desenvolvimento do psiquismo à luz da psicologia histórico-cultural}

Para adentrarmos a reflexão sobre a importância dos conceitos científicos faz-se necessário compreender o desenvolvimento do psiquismo humano. Assim, pode-se analisar a influência que a formação de conceitos científicos possui no que se refere à elevação do pensamento teórico-científico frente os dados da realidade social e, com isso, contribuir com o desenvolvimento psíquico do indivíduo.

O processo de desenvolvimento do psiquismo humano ocorre por meio de elementos e de determinações alocadas na cultura histórica e socialmente desenvolvida na essência da atividade vital do ser humano, ou seja, na categoria trabalho. Isto é, na transformação, consciente, intencional e criativa da natureza em proveito de suas necessidades (Marx, 2008).

O psiquismo humano, destarte, se traduz pela imagem subjetiva do real no interior das riquezas materiais $\mathrm{e}$ não materiais acumuladas no decorrer da história. A evolução do psiquismo humano se dá influenciada pela cultura, isto é, pelas objetivações e apropriações realizadas pelo ser humano, em dado momento histórico.

A atividade tipicamente humana assume uma função fulcral no processo de evolução do psiquismo humano. A atividade é uma estrutura (cadeia) de ações engendradas por motivos que condicionam as finalidades. Ocorre pelo aspec- 
to estrutural - atividade, operação e ação - e pelo processo psicodinâmico - motivo, finalidade e condição objetiva (Leontiev, 1978). A atividade ocorre, portanto, na relação do ser humano com a natureza, ou seja, com o mundo objetivo e, ao mesmo tempo, transforma-o em uma realidade subjetiva, ou melhor, em uma imagem subjetiva do real.

Leontiev (1978) analisa a atividade tendo em seu fundamento principal o caráter ontológico do trabalho, o qual permite que o ser humano tenha condições objetivas de se humanizar, por meio da transformação da natureza para seu benefício. Assim, inicia-se a construção de objetos/instrumentos e de procedimentos que são apropriados pelos seres humanos com o intuito de constituir um acervo de condições materiais e espirituais a fim de suprir as suas necessidades.

O ser humano, ao apropriar-se do gênero humano, realiza um salto qualitativo em que não depende mais da sua adaptação natural ao meio, pois adquiriu possibilidades mais complexas no seu contato e na transformação da natureza. Com base nessa evolução do ser humano, no âmago do trabalho, principalmente pela interação constante entre as mãos, o cérebro e a linguagem, houve um aperfeiçoamento, em um sentido anatomofisiológico, do córtex cerebral, possibilitando uma forma de relação entre o ser humano e as suas condições de existência, que ocorre definitivamente pela mediação da consciência.

A consciência é um sistema que engloba um conjunto de conhecimento que, por sua vez, é o universo simbólico que ocorre pela representação semântica da realidade, intitulou de signos por Vigotski (2002). Tal representação é um elemento do ser humano e tem como capacidade realizar a atividade abstrata, teórica e subjetiva. A consciência, por conseguinte, é a "expressão ideal do psiquismo" e, desse modo, tem-se a possibilidade de haver a existência objetivada em uma imagem idealizada psíquica, isto é, tem-se um reflexo da realidade concreta pela ideia que a consciência constrói perante essa mesma realidade.

Nesse momento ocorre uma condição ímpar na formação humana, quer dizer, há a transformação das imagens em signos e, por consequência, elabora-se o sistema de signos que podemos compreender como linguagem. A linguagem opera por meio da comunicação e do intercâmbio entre os seres humanos e também se concebe como instrumento da atividade intelectual (Martins, 2011).

É, pois, via a linguagem que a imagem subjetiva da realidade objetiva (concreta) pode transmutar-se em signos. É pela linguagem, conforme assinala Martins (2013a, p. 167168), que o indivíduo "... sintetiza o acúmulo da experiência social da humanidade ...", contribuindo, dessa maneira, com os saltos qualitativos dos indivíduos.

Há uma superação, por meio da linguagem, dos limites que se encontram alocados nas representações sensoriais através do contato imediato do indivíduo com o mundo real. Efetiva-se um salto qualitativo desse indivíduo na possibilidade de representar cognitivamente os dados da realidade por meio das palavras resultando na possibilidade de construção de ideias, que podem ser caracterizadas como os conteúdos do pensamento.
O pensamento, por sua vez, é uma expressão psíquica complexa que ocorre pelo processo produtivo modelado nas ideias, nos juízos, nos objetivos e nos conceitos que orientam e direciona a atividade humana e, concomitantemente, esse mesmo processo está subordinado àprópria atividade (Martins, 2013a).

Cabe fomentar o pensamento cumprindo a função de ir além da compreensão superficial, aparente e causal do mundo real. Deve-se, assim, incentivar a sua condição de compreender os objetos e os fenômenos na sua essência, “... promovendo a descoberta de regularidades gerais, de múltiplas vinculações e mediações que sustentam sua existência objetiva" (Martins, 2013a, p. 191). É nesse sentido que o produto dessa descoberta, realizada com base nas condições objetivas de dado fenômeno e/ou objeto, se consolide como generalização, atuando, via o pensamento, pelo movimento do geral ao particular e vice-versa.

O pensamento, destarte, é uma atividade prática do indivíduo no interior da realidade concreta. Em síntese, ocorrem no âmbito do desenvolvimento psíquico do ser humano ininterruptas mudanças evolutivas que envolvem a captação da realidade concreta e objetiva, a imagem, o signo, a palavra e a ideia (pensamento). E é no interior das ideias que se manifestam, ou melhor, se formam os conceitos.

Caracterizamos o conceito, em acordo com a psicologia histórico-cultural, como a redução da universalidade concreta da realidade, tornando-se um elemento extremamente necessário para poder estruturar e produzir nexos e determinações da atividade teórico-prática. Por meio dos conceitos é possível explicitar as características gerais e essenciais dos objetos e dos fenômenos da realidade, sintetizando e sistematizando as especificidades dos objetos e dos fenômenos.

É fulcral a necessidade de que a educação escolar e, portanto, a Educação Física, tenha como princípio atuar por meio da formação de conceitos científicos em prol da elevação do pensamento teórico-científico do indivíduo. "Potencializar o alcance possível do longo e delicado processo de formação de conceitos é, a nosso juízo, o ápice da educação escolar, na medida em que é essa formação que proporciona ao indivíduo o verdadeiro conhecimento da realidade" (Martins, 2013a, p. 304).

Com efeito, ao evidenciarmos o processo formativo de conceitos e enfatizarmos como necessário na aprendizagem e no desenvolvimento dos indivíduos, Vigotski (2010a; 2010b) destaca uma questão pertinente para a educação escolar: a distinção entre o desenvolvimento de conceito espontâneo e o desenvolvimento de conceito científico.

No entanto, cabe ressaltar que tais conceitos não se formam de maneira fragmentada ou difusa, mas sim por meio de uma unidade dialética. Não se trata de duas formas distintas de pensamento, pois se a fragilidade dos conceitos espontâneos "... se revela na sua incapacidade de abstração, no aprisionamento à experiência sensorial espontânea e imediata, a debilidade dos conceitos científicos aponta o risco de sua conversão em um 'verbalismo', em um relativo distanciamento do concreto" (Martins, 2013a, p. 222). Esses limites só podem ser superados ao longo e complexo pro- 
cesso de formação de conceitos científicos, no momento em que o verbalismo é superado pela concretude do conceito, propiciando no mote da elaboração e da utilização dos conceitos e, consequentemente, transformando-os.

Tomando essa condição como pressuposto, pode-se afirmar que o processo de conhecimento de que resultam os conceitos espontâneos não é de domínio do indivíduo. Tais conceitos são formados pelo enfrentamento imediato do indivíduo com os objetos e com os fenômenos da realidade.

Os indivíduos operando com base nos conceitos espontâneos conseguem resolver certas situações na prática, porém, por operar justamente de maneira espontânea, o mesmo não possui consciência desses conceitos. Os conceitos espontâneos se constituem apenas na experiência prática e assistemática do cotidiano (Vigotski, 2010a).

Tem-se necessidade e possibilidade de superação dessa condição sobre a formação do conceito. Efetiva-se no avanço de conceitos potenciais que perspective e "trilhe" para os conceitos que, por sua vez, contribuem, decisivamente, no procedimento real do pensamento, afluindo para operações racionais via análise e sínteses cada vez mais sistematizadas (Martins, 2013a).

Com efeito, os conceitos científicos, por sua vez, têm como princípio a atividade que media a relação do indivíduo com o objeto e o fenômeno, alocados na realidade. Portanto, esses conceitos têm um caráter consciente e intencional, cuja apropriação se dá de maneira desvinculada do contato imediato com objetos e fenômenos.

O início da formação dos conceitos científicos, na acepção de Sforni (2004), ocorre onde se estagna os conceitos espontâneos, isto é, nos desdobramentos referentes ao conteúdo, à definição verbal e na execução de ações que necessitam do emprego não espontâneo dos conceitos. A apropriação e a utilização dos conceitos científicos propicia que o pensamento se direcione mais para o conceito - atividade mental - do que para o objeto e o fenômeno de forma imediata.

Martins (2013a, p. 222), por sua vez, explicita uma condição singular sobre a formação de conceitos científicos: "Os conceitos científicos - não espontâneos - correspondem, pois, a um tipo superior de conceitos, tanto, em relação ao plano teórico quando em relação ao plano prático, formulando-se no pensamento por meio de tensões, de tarefas e problemas que exigem a atividade "teórica" do pensamento".

Eis como necessidade, no âmbito da educação escolar e, assim, da Educação Física, propiciar, por meio de um aparato teórico-metodológico, a possibilidade da formação de conceitos científicos pelos alunos. Tendo em vista que a condição de domínio do pensamento por conceitos, que contribuem na síntese de determinada objeto e/ou fenômeno, perfaz, deliberadamente, mudanças qualitativas na vida dos indivíduos. (Martins, 2013b).

Com base nessa contextualização, a função do ensino escolar é contribuir na formação de formas superiores de pensamento (pensamento teórico-científico). Destarte, deve-se atuar, no processo de ensino, em proveito da formação dos conceitos científicos (tipo superior de conceito).
Definimos, com isso, que o tipo de formação do pensamento que tanto a educação escolar como a Educação Física escolar devem priorizar, no processo de desenvolvimento do aluno, é o pensamento teórico-científico, levando em consideração a formação dos conceitos científicos.

À vista disso, compreendemos que é pelo pensamento teórico-científico que ocorre o processo de idealização das atividades objetal-prática por meio da representação em um formato universal dos objetos e dos fenômenos. Esse tipo de pensamento é desenvolvido via conceitos científicos e, assim, possibilita compreender, o mais fidedigno possível, a realidade objetiva em suas múltiplas determinações.

É com esse posicionamento, sobre a importância da formação de conceitos científicos no âmbito escolar, que tomamos como base nesse trabalho. Ou seja, compreendemos que a prática pedagógica da Educação Física deve apresentar elementos para a formação de conceitos científicos oriundos do seu objeto de conhecimento, isto é, da cultura corporal.

Vejamos, então, no próximo momento, o conceito da cultura corporal e a justificativa de apontar essa categoria como objeto de conhecimento da Educação Física escolar e, por conseguinte, transmiti-la por meio da formação de conceitos científicos.

\section{Educação Física escolar e o seu objeto de conhecimento: em questão a cultura corporal}

O debate sobre o objeto de conhecimento da Educação Física é algo recorrente no campo acadêmico dessa área do conhecimento. Há distintas teorizações que culminam em difusos objetos de conhecimento. Porém, compreendemos que o objeto de conhecimento da Educação Física é a cultura corporal, conforme explicita o Coletivo de Autores (1992).

Assinalamos a importância da reflexão sobre a cultura corporal uma vez que, o Coletivo de Autores (1992) a toma sob o embasamento do materialismo histórico-dialético. Ou seja, ao refletir sobre o objeto de conhecimento da Educação Física os autores se apoiam na concepção filosófica que engloba o método e a teoria que direcionam para uma concepção materialista histórica e dialética de mundo, de conhecimento e, por conseguinte, de conduta e ações.

O trato com os objetos e os fenômenos da realidade se dá por meio do movimento que parte das observações empíricas em direção ao concreto, isto é, vai do todo figurado na intuição a uma complexa totalidade (síntese de múltiplas determinações). Esse movimento ocorre pela mediação do abstrato (a reflexão, a análise, a formação de conceitos) que constitui uma orientação mais segura possível para que assim se possa realizar o processo da descoberta de novos conhecimentos (Marx, 2011; Saviani, 2012b).

Portanto, iniciamos a nossa explicitação sobre a cultura corporal com breves apontamentos sobre a definição de cultura, tomando como base o referencial teórico supracitado. Pois, a cultura corporal é uma "parte" do todo "complexo" que é a cultura. 
O principal pressuposto para articularmos o conceito de cultura sob os fundamentos marxianos é compreender que a cultura não pode estar desvinculada da produção social dos indivíduos. Tomamos como conceito de cultura as objetivações dos indivíduos que ocorre pela necessidade da transformação da natureza para seu benefício, ou seja, pelo trabalho. Conforme Duarte (2006, p. 118) apoiando-se nos fundamentos de Marx:

O homem, ao produzir os meios para a satisfação de suas necessidades básicas de existência, ao produzir uma realidade humanizada pela sua atividade, humaniza a si próprio, na medida em que a transformação objetiva requer dele uma transformação subjetiva. Cria, portanto, uma realidade humanizada tanto objetiva como subjetivamente. Ao se apropriar da natureza, transformando-a para satisfazer suas necessidades, objetiva-se nessa transformação. Por sua vez, essa atividade humana objetivada passa a ser ela também objeto de apropriação pelo homem, pois os indivíduos devem se apropriar daquilo que é criado pelos próprios seres humanos. Tal apropriação gera nos seres humanos necessidades de novo tipo, necessidades exclusivamente socioculturais, que não existiam anteriormente e que, por sua vez, levarão os homens as novas objetivações e a novas apropriações, num processo sem fim.

A cultura se forma e se complexifica por meio de dois processos que ocorrem dialeticamente indissociados e se explicam, fundamentalmente, pelo trabalho: 1) o processo de desenvolvimento do indivíduo como síntese de inúmeras relações sociais; 2) o contínuo processo de desenvolvimento histórico do indivíduo como um ser social (Duarte, 2013).

É por meio da relação entre a objetivação e a apropriação que se expressa na execução do processo em que o ser humano se autoconstrói na sua ação intencional e criativa, no interior da natureza, isto é, que expressa a humanização do indivíduo, a qual manifesta-se na construção contínua da cultura.

Com efeito, a cultura, atualmente, se dá na relação entre humanização e alienação, por expressarem a dinâmica contraditória que ocorre no processo de objetivação e apropriação no atual processo histórico, destacado na incessante luta de classes (Duarte, 2013).

O ser humano, ao produzir, por meio do trabalho, os meios necessários para satisfazer as condições mais elementares e mais complexas de sua existência, está humanizando a sua atividade e está se humanizando, de maneira direta ou indireta, mediado por outros indivíduos pois, conforme esclarece Duarte (2013, p. 26), “... a transformação objetiva é acompanhada da transformação subjetiva. A atividade de trabalho cria, portanto, uma realidade humanizada tanto objetiva quanto subjetivamente".

O que é a cultura, portanto, senão a transformação da natureza por parte dos seres humanos para suprir a sua necessidade (objetivação) e a sua capacidade de acumular essas transformações ou essas objetivações como bens culturais a serem apropriados pelos demais seres humanos (apropriação)? Como nos aponta Saviani (2013, p. 15): "Eis aí o processo de criação da cultura que outra coisa não é senão natureza transformada pelo homem. É no ato de autoproduzir-se pelo trabalho que o homem produz cultura".

Esse processo de objetivação e apropriação do homem que finda no processo do gênero humano faz com que "... a atividade, ao longo da história, vai construindo as objetivações, desde os objetos stricto sensu, bem como a linguagem e as relações cotidianas entre os seres humanos, até as formas mais elevadas de objetivação humana, como a arte, a ciência e a filosofia" (Duarte, 2013, p. 37-38). E, assim, no interior dessas objetivações humanas está a Educação Física e, assim, o seu objeto de conhecimento.

$\mathrm{Na}$ perspectiva do Coletivo de Autores (1992) a dinâmica curricular com ênfase na reflexão da cultura corporal busca desenvolver e intervir no âmbito do acervo das maneiras supracitadas de representação do real, no qual o ser humano se produziu historicamente e se desenvolveu socialmente. Os objetos de estudo e de ensino que a cultura corporal engloba "... podem ser identificados como formas de representação simbólica de realidades vividas pelo homem, historicamente criadas e culturalmente desenvolvidas" (Coletivo de Autores, 1992, p. 38).

O Coletivo de Autores (1992) para explicitar a apropriação, pelo ser humano, dos diversos objetos e fenômenos de que a cultura corporal é composta, sustenta-se na reflexão de Marx. Em "O Capital" (Marx, 2014), por exemplo, esse pensador analisa o processo de trabalho e aponta que há uma transformação corporal dos indivíduos em virtude de realizar um intercâmbio com a natureza para poder sanar as suas necessidades vitais. Por meio dessa ação específica do ser humano - o ato de produzir e reproduzir a sua existência - é que há uma organização corporal que se desdobra em possibilidades de efetivação da atividade vital humana, isto é, da atividade trabalho.

De acordo com Taffarel e Escobar (2009, s/p.):

Faz-se evidente que o objeto de estudo da Educação Física é o fenômeno das práticas cuja conexão geral ou primigênia - essência do objeto e o nexo interno das suas propriedades - determinante do seu conteúdo e estrutura de totalidade é dada pela materialização em forma de atividades - sejam criativas ou imitativas - das relações múltiplas de experiências ideológicas, políticas, filosóficas e outras, subordinadas aleis histórico-sociais. O geral dessas atividades é que são valorizadas em si mesmas; seu produto não material é inseparável do ato da produção e recebe do homem um valor de uso particular por atender aos seus sentidos lúdicos, estéticos, artísticos, agonísticos, competitivos, e outros, relacionados à sua realidade e às suas motivações. Elas se realizam com modelos socialmente elaborados que são portadores de significados ideais do mundo objetal, das suas propriedades, nexos e relações descobertos pela prática social conjunta. A essa área de conhecimento que se constrói a partir dessas atividades, no momento, a denominamos de "Cultura Corporal"...

A cultura corporal, nesse sentido, é construída por meio de determinadas atividades do ser humano e, portanto, faz parte da cultura de modo geral. Essa parte da cultura é 
síntese de múltiplas determinações sociais que ocorrem no processo de objetivação e apropriação dos bens sociais.

Em outros termos: a cultura corporal é síntese da atividade humana, efetivando-se via manifestações que são desdobramentos de significações construídas socialmente e de sentido consolidado em dado momento histórico. Sendo ela, em epítome, sistematizações provenientes da atividade humana não material como síntese de determinadas demandas objetivas, consolidadas de forma histórica, no qual os processos de transformações se materializam na sociedade hodierna (Frizzo, 2013).

A necessidade de apropriar-se das atividades oriundas da cultura corporal se dá na possibilidade de agir, de forma intencional, com as diversas atividades dessa categoria. Urge como condição, concreta e necessária, a transformação de determinadas circunstâncias dessas atividades, cujo objetivo se dá na apropriação da atividade em evidência. As atividades da cultura corporal devem serdesfrutadas, assim como a ciência, a filosofia e a arte. Na dicção de Nascimento (2014, p. 284), "O sujeito apropria-se dessas atividades para fazer delas as suas atividades: para fazer das capacidades humano-genéricas objetivadas nelas as suas capacidades".

A Educação Física deve, por conseguinte, abranger as relações gerais e essenciais que se manifestam em distintas atividades da cultura corporal que consubstanciam as capacidades humano-genéricas alocadas na prática social global.

Com isso, passaremos para o terceiro momento da nossa exposição, cujo principal objetivo é embasado pela articulação da psicologia histórico-cultural com a pedagogia histórico-crítica (Martins, 2013a; Scalcon, 2002).

Eis porque, de acordo com Saviani (2015, p. 41):

\begin{abstract}
...há uma intermediação entre a pedagogia histórico-crítica e a psicologia histórico-cultural que pode ser expressa nos seguintes termos: a pedagogia histórico-crítica é mediação para que a psicologia histórico-cultural se constitua como a ciência dialeticamente fundada do desenvolvimento do psiquismo humano e a psicologia histórico-cultural é mediação para que a pedagogia histórico-crítica se construa como a ciência dialeticamente fundada da formação humana tendo em vista o objetivo de produzir, em cada indivíduo singular, a humanidade que é produzida histórica e coletivamente pelo conjunto dos homens.
\end{abstract}

Partindo dessa premissa é possível apresentar elementos didático-metodológicos para a prática pedagógica na Educação Física no que se refere ao trato com o conhecimento oriundo das atividades da cultura corporal.

\section{Educação Física e prática pedagógica: elementos didático-metodológicos para a formação de conceitos científicos da cultura corporal}

A aprendizagem precede o desenvolvimento do ser humano e o ensino é a principal mediação entre esses dois elementos. Ou seja: a aprendizagem está sempre adiante do desenvolvimento, que a criança adquire certos hábitos e habilidades numa área específica antes de aprender a aplicá-los de modo consciente e arbitrário... sempre há discrepância e nunca paralelismo entre o processo de aprendizagem escolar e o desenvolvimento das funções correspondentes (Vigotski, 2010a, p. 322).

O processo de ensino e aprendizagem do conhecimento científico, por meio da formação de conceitos científicos, é fulcral para o desenvolvimento do aluno. A formação de conceitos contribui na reorganização de todas as funções psíquicas, isto é, na requalificação do sistema psíquico. Ao atuar nesse contexto, a aprendizagem escolar atinge uma importante função que é interferir na personalidade dos alunos (Martins, 2013a).

Por essa contextualização, Saviani (2008) expõe que a educação escolar deve assumir a função de planejar, de maneira intencional, a forma e o conteúdo e, assim, consubstanciá-los em elementos didático-metodológicos que evidencie concretamente o conhecimento historicamente sistematizado (científico) por meio da formação de conceitos científicos.

A prática pedagógica deve, portanto, se atentar aos princípios que influenciem o processo de formação de conceitos, em proveito da assimilação do conhecimento científico. Essa prática deve levar em consideração que os conceitos científicos não são formados e, muito menos, assimilados como apropriação da memória, mas se formam por ações problematizadoras, balizadas por elementos culturais que potencializem o pensamento em curso.

Essa aquisição dos conceitos científicos, por parte do aluno, ocorre atuando por elementos distintos e comuns com a forma de aquisição dos conceitos espontâneos. Portanto, a ligação do "... desenvolvimento dos conceitos científicos e cotidianos conflui em um mesmo e único processo - o de formação de conceitos, que se realiza em diferentes circunstâncias externas e internas" (Martins, 2013a, p. 281). Entretanto, há uma superioridade dos conceitos científicos sobre os conceitos cotidianos. Por consequência, atuar por meio da particularidade do ensino via os conceitos no decorrer do período escolar, faz com que a educação escolar conduza esse processo, sistematicamente, da formação do pensamento do aluno.

Por tais princípios, afirmamos, ainda, seguindo as orientações de Martins (2013a, p. 284), que “... em última instância, os conceitos científicos são mediados por outros conceitos em um sistema de conexões internas, apresentando o objeto ao pensamento de forma multilateral e profunda". A condição para que o aluno se aproprie dos conceitos científicos necessita, inexoravelmente, da realização do processo de generalização e abstração.

Portanto, o desenvolvimento do psiquismo humano é, impreterivelmente, dependente do ensino, ou seja, da instrução escolar. Essa afirmação se efetiva, ainda mais, ao compreender os conceitos do nível de desenvolvimento real e da área do desenvolvimento iminente. 
O nível de desenvolvimento real são conexões interfuncionais já estabelecidas pelo indivíduo. As tarefas e as ações que o indivíduo realiza, nesse nível de desenvolvimento, são identificadas por ele mesmo. Entretanto, não é pelo fato de que o indivíduo consiga identificar suas tarefas e suas ações que, esse desenvolvimento, está em um estágio finalizado. Pelo contrário, está ainda se iniciando. Tal condição se dá pelo movimento da aprendizagem, “... ao fato de que ela demanda o estabelecimento de relações internas entre funções psíquicas, convertidas em operações mentais, em conceitos e práticas" (Martins, 2013a, p. 286, grifos da autora).

Assim, como a relação entre conceitos espontâneos e científicos não podem ser compreendidos e analisados de maneira fragmentada, a relação entre esses níveis de desenvolvimento também não pode ser compreendida dessa forma.

Há, portanto, um vínculo entre o nível de desenvolvimento real e a área de desenvolvimento iminente representado pela complexificação das funções psíquicas que pautam as tarefas do ensino, no qual a referida área se apresenta como superação do nível de desenvolvimento real na direção da formação de conceitos. Por isso, Vigotski afirmou recorrentemente que, ao nível do desenvolvimento real, a formação de conceitos está sempre "começando" (Martins, 2013a, p. 287, grifos da autora).

No interior das ações na educação escolar - e, diga-se, na Educação Física - o professor tem um papel relevante. Tendo em vista que o professor possui uma visão sintética da prática social (do conteúdo a ser trabalhado) e a transmissão desse conteúdo de forma sistematizada, implicará, de forma qualitativa, no desenvolvimento psíquico do aluno, já que o professor já teria passado pela análise (pela mediação do abstrato) e, portanto, havendo salto qualitativo ao ter uma compreensão concreta.

Trazemos à discussão, portanto, nesse momento, a proposição didático-metodológica pautada na pedagogia histórico-crítica como um elemento pertinente para objetivarmos um ensino que interfira concretamente na área de desenvolvimento iminente do indivíduo, preconizando, assim, a formação psíquica cada vez mais complexa do ser humano.

A pedagogia histórico-crítica explicita um método pautado em cinco passos que devem ser compreendidos de maneira interdependentes e articulados. Esse método toma como principal pressuposto a prática social global (Saviani, 2008; 2009; 2012a; 2015) concebendo, também, de maneira intrínseca, nas suas produções a relação entre ensino (instrução escolar) e o desenvolvimento do indivíduo, conforme a psicologia histórico-cultural (Vigotski, 2002).

O primeiro passo é referente à prática social inicial, ou melhor, a prática social como início da prática pedagógica (do trabalho pedagógico). Trata-se da prática social tal como ocorre na sociedade hodierna. Professor e aluno estão inseridos no mesmo âmbito social, porém possuem distintas formas de atuar no meio que o circunda.

O professor tem uma compreensão de "síntese precária” em relação à prática social. Essa prática é sintética pela questão dos domínios que o professor já possui perante a prática social e, ao mesmo tempo, é precária, pois no ponto de partida da prática social esse agente social não conhece o nível de abstração que os seus alunos dispõem da realidade do mundo real. Já o aluno, nesse primeiro passo, possui uma compreensão "sincrética" sobre a prática social. Pois para ele não existe, ainda, uma relação entre a sua experiência no âmbito escolar e sua experiência no âmbito social para além desta.

Há, consequentemente, a necessidade de levar em consideração a estrutura da sociedade, em que os alunos estão inseridos. A intervenção pedagógica se dá no sentido de que esses alunos possam viver nessa sociedade, implicando na questão que devem compreendê-la na sua essência. É necessário, então, compreender as relações, as determinações que estão para além das aparências do fenômeno que "pairam" empiricamente à nossa percepção (Saviani, 2015).

Ao conferir esse pressuposto para a prática pedagógica da Educação Física, consequentemente, no trato pedagógico com as atividades da cultura corporal, enfatizamos que essa prática significa não ficar apenas na assimilação da informação, mas conhecer essas atividades profundamente. Necessita captar o movimento em sua totalidade, possibilitando conhecer a sua gênese, a sua estruturação, as suas contradições que metabolizam a atividade em questão e, com efeito, possa compreender as tendências de seu desenvolvimento, para que possa perspectivar e apontar possibilidade de sua transformação para uma nova formatação, levando em consideração condicionantes histórico-sociais, nas quais essas atividades estão inseridas.

O segundo passo é a identificação dos principais problemas oriundos da prática social. A esse momento, Saviani (2009, p. 64) intitulou de problematização. Trata-se, para o autor, nesse momento "... detectar que questões precisam ser resolvidas no âmbito escolar da prática social e, em consequência, que conhecimento é necessário dominar".

Levando em consideração a especificidade, supracitada, referente às atividades da cultura corporal, nesse segundo passo (problematização) trata-se do momento em que irá detectar questões referentes à prática social e como a educação irá encaminhar soluções para suprir tais questões elencadas. Cabe levar em consideração, dada característica da sociedade capitalista, o movimento das atividades da cultura corporal na relação contraditória entre as capacidades humano-genérica e as condições alienadoras de sua existência (Nascimento, 2014).

Após a identificação do problema da prática social a ser abordado no âmbito escolar, passa-se para o terceiro passo, que é intitulado de instrumentalização. Necessita, esse momento, efetivar a apropriação dos instrumentos, de cunho teórico e prático, cabíveis para suprir o problema evidenciado no momento anterior.

De acordo com Saviani (2009, p. 64), “... como tais instrumentos são produzidos socialmente e preservados historicamente, a sua apropriação pelos alunos está na dependência de sua transmissão direta ou indireta por parte do professor". 
Esse passo não coincide com mera assimilação do conteúdo e nem pela coleta de dados, mas sim de um momento que irá instrumentar a prática pedagógica, ou seja, é o momento que inicia o processo de apropriação dos elementos culturais (instrumentos teóricos e práticos) que são necessários para equacionar os problemas detectados sobre a prática social (o conteúdo trabalhado).

Deve-se levar em consideração, na problematização e na instrumentalização, que as atividades da cultura corporal possuem inúmeras possibilidade para nos relacionar com as capacidades humano-genéricas produzidas historicamente e desenvolvidas socialmente. Mas, ao mesmo tempo, as mesmas atividades, na atual sociedade, possuem elementos desumanizadores, realizando, assim, um estranhamento dessas atividades, na sua forma mais elaborada, para a maior parcela da sociedade, conforme já salientamos anteriormente. Com isso, deve-se compreender essa relação contraditória na sua essência, caracterizando a tendência que movimenta essa relação, e refletir e concretizar ações para problematizar e transformar a lógica conservadora que predomina nas especificidades das atividades da cultura corporal.

O quarto passo é intitulado como catarse. Para Saviani $(2009$, p. 64) “... trata-se da efetiva incorporação dos instrumentos culturais, transformados agora em elementos ativos de transformação social". O autor em questão baseia-se na fundamentação de Gramsci (1978) sobre a catarse, ou seja, levando em consideração a necessidade de elaboração superior da estrutura para a superestrutura no âmbito da consciência dos indivíduos.

Então, é pela mediação dos elementos culturais selecionados devidamente apropriados que possibilita haver a expressão sistematizada (mais elaborada) de uma nova maneira de compreender a prática social a que se ascendeu (Saviani, 2015). É no processo unitário de problematização-instrumentação que ocorre, simultaneamente, a catarse, ou seja, quando a estrutura do significado teórico e prático das atividades da cultura corporal que está sendo abordado é apropriada pelo aluno e incorporada, pela sua consciência, no formato de superestrutura. Esse é o momento que o aluno estabelece uma nova forma de ser e de se posicionar frente a sua prática social.

Nesse momento o aluno terá condições concretas em compreender as atividades da cultura corporal para além das suas aparências. Captando a gênese, a estrutura, as tendências do seu desenvolvimento e, consequentemente, apontando possibilidades para uma transformação de suas especificidades.

O ponto de chegada, ou seja, o quinto passo, é a própria prática social. No entanto, nesse momento o aluno não mais compreende os conhecimentos por termos sincréticos. O aluno transcende para o nível sintético, no qual o professor já se encontrava no ponto de partida desse método pedagógico. A elevação do aluno para o nível do professor é um ponto crucial para a pedagogia histórico-crítica, pois é por esse contexto que podemos compreender a especificidade da relação pedagógica.
Nas palavras de Saviani (2015, p. 38), ao discutir o trabalho pedagógico, sob o caráter dialético, específico da pedagogia histórico-crítica, salienta:

Pode-se concluir, então, que, pela mediação do trabalho pedagógico, a compreensão e a vivência da prática social passam por uma alteração qualitativa, o que nos permite observar que a prática social do ponto de partida (primeiro passo) em confronto com a prática social do ponto de chegada (quinto passo) é e não é a mesma. É a mesma porque é ela própria que constitui ao mesmo tempo o suporte e o contexto, o pressuposto e o alvo, o fundamento e a finalidade da prática pedagógica. E não é a mesma, se considerarmos que o modo de nos situarmos em seu interior se alterou qualitativamente pela mediação da ação pedagógica. E uma vez que somos, enquanto agentes sociais, elementos objetivamente constitutivos da prática social, é lícito concluir que a própria prática se alterou qualitativamente.

A educação escolar e, assim, a Educação Física escolar deve ser compreendida pelo ato de produzir de maneira intencional e direta no indivíduo aquilo que foi produzido histórica e socialmente pela humanidade. Ou seja, “... a educação é entendida como mediação no seio da prática social global. A prática social põe-se, portanto, como o ponto de partida e o ponto de chegada da prática educativa" (Saviani, 2012a, p. 160).

Tais elementos didático-metodológicos, consubstanciados pelo aporte teórico supracitado, são, a nosso ver, as formas cabíveis de fazer com que os alunos possam se apropriar o conhecimento científico por meio da formação de conceito científica, contribuindo para a elevação do pensamento teórico-científico. Contudo, como alertamos, este trabalho trata, ainda, de apresentar as primeiras aproximações sobre o objeto de análise, tornando-se necessário um aprofundamento maior nas categorias e nos elementos tratados.

\section{Considerações Finais}

Avaliamos e apontamos como proposição para a Educação Física escolar a prática pedagógica instruída pelos elementos supracitados. Pois, essa prática não se consubstancia nos moldes meramente técnicos ou por meio de regras estáticas voltadas para a questão operacional. É instituído o método histórico-dialético como fio condutor da prática pedagógica e do trabalho educativo, com o intuito de fazer com que o indivíduo (o aluno) possa se apropriar do conhecimento na sua forma mais elaborada - historicamente sistematizado - por meio da formação de conceitos científicos.

Afinal, é por meio da formação de conceitos científicos que se pode possibilita os indivíduos, inseridos nesse processo, a elevação da "... mera vivência à condição de saber sobre o vivido, isto é, permite avançar da experiência ao entendimento daquilo que a sustenta...". Porque “... a 
formação de conceitos ultrapassa a esfera do pensamento, subordinando a si as transformações mais decisivas da percepção, da atenção, da memória e das demais funções" (Martins, 2013a, p. 304).

\section{Referências}

Coletivo de autores. (1992). Metodologia do ensino de educação física. São Paulo: Cortez.

Duarte, N. (2006). Vigotski e o "aprender a aprender": crítica às apropriações neoliberais e pós-modernas da teoria vigotskiana $\left(4^{\mathrm{a}}\right.$ ed.). Campinas: Autores Associados.

Duarte, N. (2013). A individualidade para si: contribuições a uma teoria histórico-crítica da formação do indivíduo ( $3^{\mathrm{a}}$ ed.). Campinas: Autores Associados.

Frizzo, G. F. E. (2013). Objeto de estudo da educação física: as concepções materialistas e idealistas na produção do conhecimento. Revista Motrivivência. Florianópolis, 25(40), 192206.

Gramsci, A. (1978). A concepção dialética da história (2a ed.). Rio de Janeiro: Civilização Brasileira.

Leontiev, A. N. (1978). O desenvolvimento do psiquismo. Lisboa: Livros Horizonte.

Martins, L. M. (2011). Pedagogia histórico-crítica e psicologia históricocultural. Em A. C. G. Marsiglia (Org.), Pedagogia histórico-crítica: 30 anos(pp. 43-58). Campinas: Autores Associados.

Martins, L. M. (2013a). O desenvolvimento do psiquismo e a educação escolar: contribuições à luz da psicologia histórico-cultural e da pedagogia histórico-crítica. Campinas: Autores Associados.

Martins, L. M. (2013b). O papel da educação escolar na formação de conceitos. Em A. C. G. Marsiglia (Org.),Infância e pedagogia histórico-crítica(pp. 117-144). Campinas: Autores Associados.

Marx, K. (2008). Manuscritos econômico-filosóficos. São Paulo: Boitempo.

Marx, K. (2011). Contribuição à crítica da economia política (4a ed.). São Paulo: Martins Fontes.

Marx, K. (2014). O capital: crítica da economia política. Livro I: o processo de produção do capital. São Paulo: Boitempo.

Nascimento, C. P. (2014). A atividade pedagógica da educação física: a apropriação dos objetos de ensino e o desenvolvimento das atividades da cultura corporal. Tese de Doutoramento em Educação. Faculdade de Educação, Universidade de São Paulo, São Paulo.

Sánchez Gamboa, S. A. (2012). Pesquisa em educação: métodos e epistemologias ( $2^{\mathrm{a}}$ ed.). Chapecó: Argos.

Saviani, D. (2008). Pedagogia histórico-crítica: primeiras aproximações (10 ed.). Campinas: Autores Associados.

Saviani, D. (2009). Escola e democracia $\left(41^{a}\right.$ ed.). Campinas: Autores Associados.

Saviani, D. (2012a). A pedagogia no Brasil: história e teoria (2a ed.). Campinas: Autores Associados.

Saviani, D. (2012b). Marxismo, educação e pedagogia. Em D. Saviani \& N. Duarte (Orgs.),Pedagogia histórico-crítica e luta de classes na educação escolar(pp. 59-86). Campinas: Autores Associados.

Saviani, D. (2013). "Prefácio". Em Martins, L. M. O desenvolvimento do psiquismo e a educação escolar: contribuições à luz da psicologia histórico-cultural e da pedagogia histórico-crítica(pp.13-16). Campinas: Autores Associados.

Saviani, D. (2015). O conceito dialético de mediação na pedagogia histórico-crítica em intermediação com a psicologia históricocultural. Revista Germinal: marxismo e educação em debate, 7(01), 26-43.

Scalcon, S. G. (2002). À procura da unidade psicopedagógica: articulando a psicologia histórico-cultural com a pedagogia histórico-crítica. Campinas: Autores Associados.

Sforni, M. S. F. (2004). Aprendizagem conceitual e organização de ensino: contribuições da teoria da atividade. Araraquara: JM Editora.

Taffarel, C. N. Z. \& Escobar, M. O. (2009).Cultura corporal e os dualismos necessários a ordem do capital. Boletim Germinal, 09. s.p.

Vigotski, L. S. (2002). A formação social da mente: o desenvolvimento dos processos psicológicos superiores ( $7^{\mathrm{a}}$ ed.). São Paulo: Martins Fontes.

Vigotski, L. S. (2010a). A construção do pensamento e da linguagem ( $2^{\mathrm{a}}$ ed.). São Paulo: Martins Fontes.

Vigotski, L. S. (2010b). Psicologia pedagógica (3a ed.). São Paulo: Martins Fontes. 


\section{Sobre o autor}

Matheus Bernardo Silva (matheusbernardo25@gmail.com)

Licenciado em Educação Física pela Universidade do Extremo Sul Catarinense (UNESC). Doutorando em Educação pela Universidade Estadual de Campinas (UNICAMP). Professor Substituto na Universidade Federal do Paraná (UFPR). Membro do Grupo de Estudos e Pesquisas "História, Sociedade e Educação no Brasil" (HISTEDBR). 